\title{
Propuesta teórico-metodológica para el análisis de las noticias sobre "Los 33 mineros de Atacama" (Chile) publicadas en los diarios El Comercio del Perú y La Razón de Bolivia.'
}

Carlos del Valle Rojas (Universidad de La Frontera, Temuco-Chile), Rodrigo Browne Sartori, Julio Carvajal Rivera, Norma Huerta Andrade, Pamela Romero Lizama (Universidad Austral de Chile, Valdivia-Chile)

RESUMEN: Este artículo busca desarrollar una propuesta teórico-metodológica de análisis para comprender los procesos de construcción social de la realidad y las representaciones que los principales medios de prensa escrita de Perú y Bolivia realizaron acerca del cautiverio y rescate de los 33 mineros atrapados en el yacimiento San José, Chile, en el 2010.

Palabras clave: Periodismo intercultural / comunicación intercultural / construcción internacional de la noticia / análisis crítico del discurso (ACD)

Theoretical-methodological proposal for analyzing the news about "The 33 miners of Atacama" (Chile) published in the newspaper El Comercio of Peru and La Razón of Bolivia

АвsтRAст: This article seeks to develop a theoretical-methodological analysis to understand the processes of social construction of reality, and the representations that the mainstream press in Peru and Bolivia presented about the captivity and rescue of the 33 miners trapped in the San José mine, Chile, in 2010. Keywords: Intercultural journalism / intercultural communication / international construction of news / critical Discourse analysis (CDA)

1 Este artículo forma parte de los proyectos DID-UACh S-2011 “Análisis crítico de la representación social en la prensa escrita: los casos de la huelga de hambre mapuche y el rescate de los mineros del yacimiento San José en los diarios La Cuarta y El Mercurio (Dirección de Investigación y Desarrollo de la Universidad Austral de Chile, 2011-2013) y del proyecto Fondecyt 1100264 “Periodismo intercultural: Construcción de la noticia a través de 


\section{Introducción}

$\mathrm{E}$ 1 objetivo de este artículo es proponer las bases teórico-metodológicas -y presentar un ejemplo por país- para analizar los contenidos informativos que hacen los medios de comunicación escritos sobre sucesos internacionales de interés mundial como es, en este caso, la representación noticiosa publicada en los diarios El Comercio del Perú y La Razón de Bolivia acerca del derrumbe y rescate de los 33 mineros atrapados en el yacimiento de cobre y oro San José, en la ciudad de Copiapó (Región de Atacama, Chile).

Esta iniciativa busca comprender los procesos de construcción de la noticia y las representaciones que dos de los principales, tradicionales y conservadores medios de prensa escrita del Perú y Bolivia realizaron sobre este acontecimiento de trascendencia internacional. En otras investigaciones ya culminadas ${ }^{2}$ se confirmó que los pe- riódicos chilenos de carácter oficialista, con fuerte línea editorial conservadora, coadyuvan a entender cómo dichas representaciones refuerzan "realidades" entre países, que sostienen imaginarios que, como estereotipos, se apartan de los discursos dialógicos e interculturales propios del periodismo transparente que debiera ejercer la prensa al reconocerse como una de las fuentes primarias de producción de prejuicios socioculturales (van Dijk 2003, Rodrigo 1989 y 2001). En el caso particular, por ejemplo, de los diarios chilenos La Tercera y El Mercurio se obtuvo como resultado un marcado nacionalismo que, entre sus construcciones de noticias, menoscaban las diferencias culturales de los países limítrofes entendidas, para efectos de estos proyectos, como lo publicado sobre lo peruano y lo boliviano.

De este modo, la propuesta tiene como objeto de investigación comprender las discusiones derivadas de los intercambios epistemológicos en-

un análisis crítico y complejo del discurso en la prensa diaria de cobertura nacional de Chile y el Perú. El caso de El Mercurio y La Cuarta y El Comercio y Ajá (Comisión Nacional de Investigación Científica y Tecnológica [Conicyt], Ministerio de Educación, Chile, 20102012.

2 2010-2012: Proyecto Fondecyt 1100264 “Periodismo intercultural: Construcción de la noticia a través de un análisis crítico y complejo del discurso en la prensa diaria de cobertura nacional de Chile y Perú. El caso de El Mercurio y La Cuarta y El Comercio y Ajá (Conicyt, Ministerio de Educación, Chile y 2007-2009- Proyecto Fondecyt 11070062 “Comunicación intercultural y periodismo intercultural: análisis crítico de la construcción social de la realidad a través de la representación mapuche y peruano-boliviana en las noticias de la prensa diaria de cobertura nacional (Copesa y El Mercurio)" (Conicyt, Ministerio de Educación, Chile). Sobre todo en este último proyecto los resultados fueron determinantes para evidenciar que los medios de prensa mencionados tienden a instaurar e incentivar 
tre cultura y comunicación, puntualizados en el ámbito del periodismo intercultural y las representaciones que se hacen en los medios de prensa sobre la construcción de las identidades. Para esto se aplicará una estrategia de carácter cualitativo derivada del análisis crítico del discurso (ACD) basada, principalmente, en lo estipulado por Teun van Dijk (1990 y 1997) en sus ya reconocidas investigaciones.

En consecuencia, y al finalizar la puesta en marcha de este proyecto, esbozado a nivel de propuesta en este artículo, la idea es: a) analizar cómo los diarios El Comercio del Perú y La Razón de Bolivia construyen acontecimientos noticiosos en virtud de las relaciones que tienden a fortalecer la conformación identitaria de su Estado-nación; b) estudiar cómo la prensa, a través de la construcción de la noticia en temáticas interculturales, representa los "discursos de la diferencia", especialmente en las proyecciones noticiosas del cruce Perú-Bolivia-Chile; y c) describir cómo los medios de prensa, con una de las mayores lectorías y que representa a un sector conservador de la sociedad en Perú y Bolivia, respectivamente, contribuyen a la construcción social de la realidad intercultural de su país.

\section{Propuesta teórica}

El estado de la investigación a nivel nacional e internacional en torno a la comunicación en espacios socioculturales limítrofes y a la construcción de identidades, permite proponer los siguientes apartados de discusión teórica:

\section{Comunicación intercultural mediada}

\section{Cultura y comunicación mediada}

La comunicación mediada se ha tornado en un tema de vital interés para los investigadores de las comunicaciones en el nuevo siglo (Piñuel y Lozano 2006), sobre todo para quienes reflexionan desde la relación comunicación y cultura. Miquel Rodrigo Alsina (1999) sostiene esta posición indicando que los nuevos aportes desde y para la comunicación mediada se proyectan como parte de acciones propias de los tiempos, tales como: a) conciencia de una mundialización producto de la globalización económica y comunicacional; b) globalización que implica la intervención de organismos internacionales en conflictos regionales o nacionales; y c) multiplicación de conflictos interculturales.

Vale decir, la comunicación también cobra una relevancia geopolítica

imaginarios que desvalorizan en sus páginas las "alteridades" y "diferencias", en contraposición con la identidad nacional-chilena aquí analizada. 
entendida, esta última, como un campo del saber donde diferentes disciplinas permiten un análisis multi e interdisciplinario de la relación del ser humano con el territorio. De acuerdo con el Observatorio Austral de Geopolítica ${ }^{3}$ tres conceptos ocupan el espacio intelectual de esta: a) la problemática del territorio y del espacio como ámbito material y virtual de las prácticas sociales humanas; b) la naturaleza del grupo humano como actor histórico situado en la historia y en la geografía; y c) la problemática del poder como práctica política y simbólica y como modo de apropiación del territorio.

Del encuentro entre estas dimensiones surge la geopolítica como una interrogación intelectual acerca del modo como los grupos humanos ocupan, se apropian, utilizan y se sirven de los territorios en el ejercicio de su poder.

Con estos antecedentes es necesario abordar -primero y someramente- el concepto de cultura, el cual es entendido por Tomás Austin Millán (2000) como un entramado de significados compartidos. Significados que obtienen su connotación del contexto (geografía, clima, historia y procesos productivos), pero que habita en la mente de los individuos dándoles una identidad cultural específica, es decir, "se justifica el argumento teórico que nos dice que la cultura está tanto en la mente de los individuos como en el ambiente en que ellos viven" (Austin 2000: 16).

Complementando la idea de contexto que se plantea en el enunciado anterior, Juan Luis Fuentes (2006) agrega que este condiciona, además, el hecho comunicativo. Idea importante al momento de volcarnos al producto periodístico, en tanto este hecho será condicionado por el contexto en el que se exprese y desde donde se exprese, lo cual se propone verificar esta propuesta de proyecto revisando la construcción de la noticia en espacios geopolíticos de conflicto intercultural, como la cobertura periodística del suceso "Los 33 mineros de Atacama, Chile" por el diario El Comercio de Perú y La Razón de Bolivia.

En cuanto al concepto de comunicación se podría afirmar que sus aproximaciones teóricas han mutado desde la transmisión entre las máquinas y las nuevas tecnologías de la información y la comunicación, hasta las relaciones culturales (Mattelart y Mattelart 1997), entre otras tendencias. A partir de las relaciones culturales, Sebastiá Serrano define comunicación como el "proceso por el cual unos seres, unas personas, emisor y receptor(es), asignan significados a unos hechos producidos y, entre ellos, muy especialmente, al comportamiento de los otros seres

3 Observatorio Austral de Geopolítica (2011), en <http://geopoliticasur.wordpress.com/ geopolitica-geopolitica>. 
o personas" (1984: 38). El autor recalca la importancia de los procesos de interacción entre los seres humanos, los cuales el periodismo evidencia a través de la construcción de la noticia $\mathrm{y}$ en los actos comunicativos que son aquellos en los que se asignan significados, "donde se dota de sentidos al mundo que nos rodea, poniendo especial énfasis en el actuar de los demás".

Por su parte, José Luis Piñuel y Carlos Lozano (2006) toman una línea similar a la hora de referirse a la comunicación como campo de investigación. Para ellos no es lo mismo "saber comunicarse" que "saber de comunicación". Comunicarse tiene que ver con la práctica, con experiencias sociales y culturales en las que se van adquiriendo habilidades para tener éxito en el actuar. La comunicación en tanto hace referencia a un saber reflexivo sobre las prácticas comunicativas en un contexto cultural. Al respecto Grifeu (1991) indica que la comunicación debe ser vista como un proceso histórico simbólico e interactivo, en donde la realidad social es construida por los seres humanos en un determinado contexto y, a la vez, construye diferentes realidades sociales para las personas.

En relación con las coordenadas comunicación y cultura, Miquel Rodrigo Alsina (1999) propone una nueva forma de participar activamente en los conflictos y choques entre culturas (Mattelart y Mattelart 1997, Romano 2000), denominando comunicación intercultural mediada a una propuesta teórico-conceptual que tiende al encuentro y tolerancia entre "diferentes". La comunicación intercultural mediada es un espacio donde -sin ser su centro- se asume la intervención tecnológica y se habla de los procesos de mediación que se dan en la producción del mensaje, no solo utilizando el medio como mero transmisor (como canal), sino que, además, validándolo como constructor de un discurso determinado en un contexto global/local. Con esto, el autor argumenta que las comunicaciones buscan "entender cada cultura a partir de su propio universo simbólico" (1999: 33).

En este plano, también Estrella Israel Garzón (2004 y 2006) y Andreu Casero Ripollés (2004) afirman que la mayor parte de los conocimientos sociales y culturales - por tanto la mayor parte de nuestras opiniones- se construyen desde las informaciones que entregan los aparatos productores de noticias. Es decir, prácticamente todo lo que la mayoría de los hombres conocen de otras culturas diferentes a la suya es suministrado por reportajes, noticias, sitios web que, para efectos de esta propuesta de análisis, se estudiará desde un diario peruano y otro boliviano de influencia nacional, con repercusiones al momento de construir la realidad identitaria-cultural de "otra" nación vecina.

Por último, es necesario señalar que la comunicación intercultural mediada y sus particulares características evidencian que los medios 
de prensa se dejan llevar en general por los discursos institucionalizados y legitimados, particularmente en espacios geopolíticos de "conflicto", manteniendo el estado de la cuestión a la hora de consolidar construcciones de realidad y olvidando, dentro del rigor periodístico, abrir espacios de convivencia y armonía entre diferentes actores de un hecho noticioso. En tal sentido, se considera necesario recuperar las nociones que se han expuesto en relación con un periodismo intercultural (Israel [2000] y [2004], Browne, Inzunza y Valenzuela [2009] y Browne et al. [2011]) que se pregunta sobre dichas representaciones y construcciones al observar el ejercicio de la prensa en dos países del sur de América Latina, en coherencia con un acontecimiento noticioso celebrado en otro país, considerando las ya presentadas aproximaciones en torno a la comunicación intercultural mediada.

\section{Construcción de la realidad intercultural}

Berger y Luckmann (1972), a partir de la sociología del conocimiento como espacio reflexivo, plantean que el estar en una sociedad, incluirse en ella, es participar de su dialéctica. Cuando el individuo se concibe como parte de una sociedad, comienza a establecer ciertas normas de convivencia que serán dadas por los otros y por el propio individuo, siendo estas parte del proceso de su subjetivación. Con esto, los autores explican que un individuo conforma su propia identidad, solo si es parte de un mundo, de un todo que lo forma y se forma a partir de la conciencia de sus existencias mutuas. Así, se va configurando subjetivamente la identidad del individuo.

En relación con lo anterior y bajo los intereses de esta propuesta de análisis, la comunicación intercultural, entendida como campo de estudio teórico y práctico -al momento de analizar la construcción social de la realidad entre culturas- permite analizar el discurso periodístico. En particular, el ámbito concebido como la construcción internacional-intercultural de la noticia, que asoma como un componente crucial porque trata los hechos ocurridos en la cultura del país vecino, donde

[...] la propuesta de periodismo intercultural reside tanto en la actividad ejercida por los periodistas en aquellos lugares a los que acuden como corresponsales [...] como así mismo en los encuentros que se establecen en el propio medio (Israel 2000: 34).

Rodrigo (1989: 122) plantea que los medios desarrollan técnicas para decir más cosas en el mínimo espacio y donde es común el uso de estereotipos: "Estereotipar es una forma muy fácil de ponerse de acuerdo con la audiencia porque, en la mayoría de los casos, los estereotipos son percepciones en gran parte compartidas". La instauración de un estereotipo resulta muy difícil de olvidar ya que entrega rápidas explicaciones sobre una situa- 
ción recientemente ocasionada, colaborando en la construcción social de realidad, para efectos de este trabajo, intercultural.

Asimismo, Vicente Romano (2000) insiste en que siempre hay un sesgo tras el uso de los medios y esa decisión procede directamente desde aquellos grupos que se vinculan con el poder económico, político y social. Las informaciones provenientes de estos medios que pasan a formar parte de la visión de mundo de una sociedad, con características distintivas asimiladas y cultivadas, están dirigidas e intencionadas con un fin determinado,

[...] una intervención inconsciente en el material comunicativo con unos intereses muy concretos. Cualquier proceso de producción comunicacional, desde la elección del medio, la grabación, la mezcla y la distribución, es una intervención en el material existente (Romano 2000: 5).

No solo hay que conformarse con que los medios se refieran a otras culturas, sino que también hay que preocuparse de cómo representan esa diversidad cultural, ya que esta no queda reducida a una simple promesa incumplida dentro de los ejercicios periodísticos-culturales (Glasser, Awad y Kim 2009). "La conocida tendencia de este medio a destacar lo negativo debería atemperarse cuando se trata de describir culturas" (Rodrigo 1999: 11). Este último autor concluye que para que el proceso de construcción de la realidad social se cumpla de manera correcta, dependerá absolutamente de la práctica del periodismo, mientras tanto, Berger y Luckmann (1972) dicen que el periodista es y debe ser tratado como un constructor de información.

Se torna urgente, por lo expuesto con anterioridad, establecer procedimientos para favorecer el periodismo desde un contexto intercultural: "una apuesta por un periodismo de calidad en un mundo complejo y convergente donde la interculturalidad como pauta se configure como una necesidad creciente" (Israel 2002: 1).

\section{El periodismo y el medio de comunicación social como constructores de noticias}

\section{El periodismo en la sociedad actual}

Explica Jesús Martín Barbero (1987) que hasta no hace muchos años el mapa cultural de los países latinoamericanos era el de miles de comunidades homogéneas pero aisladas, dispersas, casi incomunicadas entre sí y muy débilmente vinculadas a la nación. Sin embargo, afirma que hoy el mapa es otro: América Latina vive un desplazamiento del peso poblacional del campo a la ciudad que no es meramente cuantitativo sino el indicio de la aparición de una trama cultural urbana heterogénea, formada por una densa multiculturalidad que da cuenta de modos de vivir, de pensar, de sentir y de narrar que están ampliamente comunicados y, además, expuestos. 
Las prácticas de comunicación y cultura asociadas a espacios geopolíticos limítrofes permiten el desarrollo de procesos de comunicación social propios de la época, donde junto con abrirse canales de múltiples transmisiones de contenidos se llegan a establecer espacios informativos comunes, como vínculos que fortalecen las bases de la colectividad, dando paso al surgimiento de un 'periodismo internacional', que asume que los sucesos foráneos son un vehículo hacia una mejor evaluación y visión de las realidades vecinas. Dicha actividad gira en torno a lo que se conoce universalmente como "la información", la cual en opinión de Gonzalo Abril (1997) no es ya un concepto formal (estadístico, cibernético o cognitivo), sino un fenómeno histórico y socialmente determinado. En la época premoderna puede hablarse de ideas, saberes o representaciones, pero no de información. La información se desarrolla en el mismo proceso de expansión de la imprenta y de las publicaciones impresas porque se da un nuevo despliegue con la adopción de medios de comunicación electrónicos y "llega a adquirir una importancia central en la organización social, política y cultural del mundo contemporáneo" (Abril 1997: 33).

Desde esta perspectiva, la demanda comunicativa experimentada por los diferentes estratos socioculturales ha originado profundos cambios en la visión del periodismo internacional. A juicio de Aymara Bracho (2006), es- tos cambios han impactado en la idea que se tiene de las diferentes naciones, partiendo de lo que publican o dejan de publicar los diarios locales y nacionales de cualquier parte del mundo. La labor periodística foránea se perfila como herramienta de expansión de cultura y de transmisión de conocimientos a la colectividad:

De esta manera, los medios de comunicación impresos han creado una conexión entre temas políticos, económicos, sociales y culturales, o de cualquier otra índole, que tengan lugar en cualquier país, para darlo a conocer en sus esferas locales (Bracho 2006: 12).

Ante este panorama, se puede decir que el periodismo internacional juega un papel de interés en los sistemas de comunicación pública, en los que la información extranjera divulgada ofrece criterios cada vez más amplios y que van más allá de las relaciones interpersonales. Afirma Bracho (2006) que la oleada internacional de noticias en la prensa nacional indica que empresas informativas, editores y redactores, han de asumir el reto de estar dispuestos a enfrentar los grandes desafíos de la globalización, más aún cuando la interconexión entre países se aprecia como una actividad fundamental para el desarrollo de las poblaciones que sean capaces de enfrentar sus propias competencias, y las que le impongan las sociedades con mayor progreso.

La actividad periodística, en este punto y como se ha esbozado, es par- 
te fundamental de la construcción de la sociedad porque está legitimada y funciona como manifestación de consensos sociales. El periodismo presenta la realidad social y permite su observación, comprensión y análisis (Browne y Romero 2010). Es así como su principal componente: "la noticia", y en este caso su construcción internacional, se torna en una tecnología que produce lo real, tomando como base un discurso verosímil que proviene de unidades artificiales -como son las fuentes- y naturales -como los hechos- de un acontecimiento noticioso, "con el objetivo de predecir determinadas repercusiones y mantener un control de la realidad social" (Mayorga y González 2005: 3). Vázquez Medel (1999) -también inspirado en el trabajo de Berger y Luckmann- indica que el periodismo escrito constituye una forma de institucionalización de los procesos de construcción social de la realidad: "surge como respuesta a nuevas necesidades de consensos sociales y se transforma al ritmo de nuevas posibilidades tecnológicas y económicas, y de nuevas interacciones" (Vázquez 1999: 149). Así, el periodismo representado por los medios de comunicación es uno de los principales constructores de imágenes para la institucionalización de una identidad.

Desde hace décadas, el periodismo se entiende como una empresa, con prioridades económicas, cuyo objetivo principal es la producción y difusión de mensajes informativos (Carvajal 2007), haciendo, especialmente, que estas noticias sean parte de un discurso construido que tenga como referencia la realidad o, por lo menos, una fracción de ella. Por esta razón hay que analizar el rol que cumplen los medios de comunicación y el periodismo en la formación de los imaginarios o universos simbólicos de cada individuo y de un colectivo determinado, debido a que la configuración social es una construcción constante que se edifica con la interacción del entorno sociocultural. Los medios de comunicación ejercen una gran influencia sobre los individuos, modelan las identidades y separan a los grupos, aunque hacen alarde de unir, mediante sus discursos, a las diferentes culturas, países y etnias que forman parte de su universo noticioso.

Por tanto, podemos concluir que los medios de comunicación de masas no son solo transmisores de acontecimientos e información, sino también constructores de realidad, agregando a esto que son creíbles y veraces para las personas, aumentando su poder comunicacional. Así también, los medios se encuentran influenciados por múltiples ideologías que marcan su pauta editorial. Y dentro de estos, los periodistas tienen el rol y la atribución de elegir los temas de interés y construir un texto según la discriminación que ellos hacen de los puntos importantes del acontecimiento, dotándolo de sentidos. 


\section{Construcción internacional de la noticia}

El análisis del discurso periodístico permite examinar la construcción internacional de noticias producidas por los medios. En el proceso de construcción social de la noticia es importante definir qué se entiende por esta. Rodrigo, en términos generales, precisa que noticia es un hecho verdadero, inédito o actual que puede llegar a un público de carácter masivo, "una vez que ha sido recogido, interpretado y valorado por los sujetos promotores que controlan el medio utilizado para la difusión" (Rodrigo 1989: 185).

A su vez, continúa definiéndola como "una representación social de la realidad cotidiana producida institucionalmente, que se manifiesta en la construcción de un mundo posible" (Rodrigo 1993: 18), explicando sus alcances de la siguiente manera: a) la representación social es una actividad que implica la reproducción de las características de un objeto que se traduciría en una construcción mental de éste; b) que es producida institucionalmente, esto es que la noticia tiene tanta importancia en su producción como en su reconocimiento institucional, que es llevado a cabo por un periodista que se solidariza con "las reglas del juego", certificando y validando a la propia sociedad; y c) construcción de un mundo posible que hace referencia a los estados de cosas previstas por el lector, es decir, y desde un punto de vista narrativo, se puede afirmar que la construcción del discurso periodís- tico informativo supone la creación discursiva de un supuesto mundo posible:

De algún modo se puede comparar al periodista como una especie de lector privilegiado de acontecimientos, a partir de los cuales va construyendo mundos posibles que luego transmitirá al auditorio (Rodrigo 1989: 187).

Para este autor es importante establecer que las "noticias" nacen desde un "acontecimiento" al que el periodista le otorga sentido. Por tanto, es substancial señalar la diferencia entre estos dos conceptos. Se podría marcar una distinción entre el "acontecimiento" de la "noticia" diciendo que el primero de estos es un mensaje recibido, mientras que la segunda es un mensaje emitido. "Es decir, el acontecimiento es un fenómeno de percepción del sistema, mientras que la noticia es un fenómeno de generación del sistema" (Rodrigo 2006: 7).

Por consiguiente, el mundo que hemos denominado "real" correspondería a los hechos, datos y circunstancias que son conocidos por el periodista. Hechos, por así decirlo, sin calificación. Hechos que remitirán a un número determinado de mundos de referencia. $\mathrm{Y}$ a partir de estos mundos de referencia será cómo el periodista podrá determinar el tipo de acontecimiento que tiene que relatar.

En este plano de análisis y cuestionamiento de las noticias, es relevante el trabajo de Teun van Dijk, a través 
de un $\mathrm{ACD}$, cuyo principal objetivo es elucidar una estrategia que permita comprender el discurso, en este caso periodístico, peruano y boliviano, sobre una noticia particular chilena.

Van Dijk (2003) define el análisis del discurso como una especie de investigación exhaustiva o desglose de términos que estudia tanto el texto como el habla de los discursos en todas las perspectivas posibles, principalmente para descubrir el abuso del poder social y cómo la desigualdad es practicada, en lo cotidiano, junto a la hegemonía. Para esto se pueden identificar tres aspectos principales en el ACD: los actos del habla, los significados y las formas de oración.

Según van Dijk, esta propuesta tiene como objeto evidenciar los problemas sociales, refiriéndose a la injusticia sobre el poder y la desigualdad. Describe que el poder de los medios de comunicación es, por lo general, imaginario y persuasivo.

Conjuntamente se refiere al poder del discurso en la construcción social; tanto en las creaciones ideológicas como en los abusos, surge el ACD como un instrumento imprescindible para vislumbrar a los reproductores de estereotipos e ideologías:

Los sujetos sociales más poderosos pueden controlar el discurso seleccionando el lugar, los participantes, las audiencias, los actos del habla, tiempo, los temas, el género, los estilos (Van Dijk 1994: 14).
Con el propósito de contextualizar la formulación teórica del presente proyecto al analizar hasta qué punto los medios influyen en nuestras vidas $y$, por tanto, en nuestras concepciones sobre otras culturas, naciones y sociedades, es preciso destacar lo afirmado, tiempo atrás, por Maxwell McCombs (1996), en su libro Influencia de las noticias sobre nuestras imágenes del mundo:

Las noticias influyen en muchas facetas de nuestra vida cotidiana. Nuestro modo de vestir para ir al trabajo, el camino que elegimos a veces para llegar a él, los planes del próximo fin de semana, nuestros sentimientos generales de bienestar o de inseguridad, el enfoque de nuestra atención hacia el mundo más allá de la experiencia inmediata y nuestras preocupaciones sobre los temas del día, están bajo la influencia de las noticias cotidianas (McCombs 1996: 38).

\section{Propuesta metodológica}

En coherencia con esta propuesta que busca analizar los procesos de construcción de la noticia a partir de dos medios periodísticos líderes de opinión y de circulación nacional en Perú y Bolivia, respectivamente, en relación con el acontecimiento informativo de los 33 mineros atrapados en una mina, en Chile, se propone una metodología de investigación basada en el (ACD) periodístico (Van Dijk 1997 y 2003) que se desprende de la matriz elaborada y aplicada en trabajos cua- 
litativos hermenéuticos ya validados como herramienta de análisis, en otros estudios sobre tratamiento de prensa internacional e intercultural, y donde el equipo investigador que suscribe ha participado activamente (Browne, Del Valle, Carvajal, Huerta y Romero 2009, 2010, 2011), como es el caso también de los trabajos en torno al análisis complejo y crítico del discurso (ACCD) (Del Valle 2006).

En línea con lo propuesto y de cara a una proyección metodológica sociocognitiva, diversa e interdisciplinaria, para comprender los procesos de construcción noticiosa internacional e intercultural, se propone la aplicación de una matriz, de lo general (global) a lo particular (local) en aspectos formales y de significados (Van Dijk 2003), que se dividirá en cuatro niveles, presentados en dos planos: ${ }^{4}$

\section{Plano significado/texto}

1.1 Nivel temático: significados globales. Se refiere a los temas de los "que trata" el discurso periodístico-informativo analizado, marcando las interacciones, la estructura social y las orientaciones de "cómo" se emite la noticia. En la práctica, estos "significados globales" (Van Dijk 2003), generalmente, no pueden ser reconocidos con tanta evidencia, sino que deben ser inferidos del propio discurso o, en el último de los casos, asignados a él.

Con esto se obtendrá una primera idea general de la noticia analizada y se controlarán otros aspectos generales. En el periodismo este plano de abstracción consiste en un conjunto de categorías textuales convencionales, tales como portada, llamadas y texto que conforma la noticia, las opiniones y los comentarios. Por otra parte, los periodistas otorgan a sus titulares una estructura de relevancia del texto, es decir, tratan de esquematizar lo esencial entre el epígrafe y el título de la noticia.

Se intentará buscar respuesta a varias interrogantes, tales como: de qué habla el texto, qué macroestructuras semánticas son posibles deducir del discurso, cómo se unen, cuáles son los presupuestos que se manejan acerca del discurso sobre el acontecimiento noticioso que ocupa a este proyecto.

1.2 Nivel de significados locales. Se refiere a un estudio de los "significados locales" como, por ejemplo y bajo los intereses prioritarios de esta investigación, el significado literal de las

4 Como anexo se adjunta un ejemplo de la aplicación de esta matriz en sendas noticias sobre los mineros en los diarios El Comercio de Perú y La Razón de Bolivia. 
palabras. Los significados locales, a diferencia de los significados globales, resultan del vínculo que se establece entre quienes emiten la noticia en función de los modelos mentales de quienes reciben la información, y sus posteriores opiniones, actitudes y construcciones sociales.

Las formas de significados locales se pueden dividir en dos categorías:

1.2.1 De carácter implícito o indirecto: informaciones que se pueden inferir de palabras del texto como implicaciones, presupuestos, alusiones, ambigüedades, hipérboles, etcétera. El texto no lo expresa explícitamente. Este tipo de significado local es parte del modelo mental del público y no está presente con evidencia en el texto analizado. Es decir, la intención en el uso de determinadas palabras al nombrar detalles supuestamente irrelevantes, es donde los analistas críticos del discurso deben colocar especial atención.

1.2.2 De carácter explícito o directo: informaciones evidentes que se encuentran con claridad en las palabras del texto. Particularmente, en este paso, interesa indagar acerca de las estrategias léxicas utilizadas por los periodistas en las informaciones de prensa o noticias sobre las temáticas del nivel anterior. Esto permite observar qué palabra es la más utilizada por los medios de comunicación en determinadas informaciones. Saber qué implicancias tiene la elección de tales conceptos en relación con los 33 mineros de Atacama (Carvajal et al. 2011). ${ }^{5}$ Otros factores que se deben tomar en cuenta son el estilo y la retórica que se verifican en el resultado textual de escribir-por medio de la elección de distintas palabras-y publicar un texto que podría decir lo mismo "con sinónimos". Dichas elecciones estilísticas también conllevan implicaciones ideológicas que pueden dar a entender la opinión del periodista y del medio, en general, sobre el suceso.

\section{Plano formal/texto-contexto}

2.1 Estructuras formales sutiles. Se refieren a las formas o formatos globales y locales que se pueden caracterizar por incidir menos en el control consciente de las

5 Trabajo adelantado en Carvajal, Browne, Alfaro, Huerta y Romero (2011). Proyecto DID № S-2011-25, Universidad Austral de Chile: “Análisis crítico de la representación social en la prensa escrita: los casos de la huelga de hambre Mapuche y el rescate de los mineros del yacimiento San José en los diarios La Cuarta y El Mercurio". 
noticias por parte de los receptores. Su objetivo es, en principio, observar cómo operan los aparatos ideológicos formales del discurso que pueden emitir falacias, omitir información crucial, construyendo modelos sesgados e interesados de acuerdo con los "discursos de dominación" y sus fuentes. Discursos que difunden este hecho noticioso y que no se perciben, debido a su sutileza, en el carácter indirecto del plano del significado. Aparato ideológico invisible, activado a partir de la información emitida. Inconscientemente se está marcando un "ellos" y un "nosotros", donde "ellos" como "otros" son los que producen el conflicto internacional.

2.2 Nivel contextual. Son representaciones mentales de la memoria a largo plazo, en la que se almacenan los conocimientos y las opiniones sobre lo vivido. Se refiere a la importancia que tienen en relación con los contextos modélicos locales y globales. En síntesis, lo que se recordará, posteriormente, es el modelo mental que se construye a partir de lo emitido contextualmente en la construcción social de la realidad (Berger y Luckmann 1972) y su aproximación al periodismo en la construcción de la noticia (Rodrigo 1989). La diferencia con las estructuras formales sutiles se encuentra en el marco contextual que descansa en cuestiones históricas, políticas, económicas y sociales que confirman el vínculo entre el discurso y la cultura. El conflicto peruano-boliviano-chileno está plagado de relaciones y futuras publicaciones ligadas a un contexto geopolítico de siglos, que marcan la pauta noticiosa de uno y otro lado de las fronteras.

En reiteradas ocasiones, se menciona que el análisis crítico del discurso no se limita solamente a detallar las estructuras textuales que expresan varios significados subyacentes, a fin de mostrar cómo este significado implícito se relaciona con el texto (de lo cual se ocupa el plano del significado). También se deben tener presentes los contextos cognitivo, histórico, social, político y cultural. Van Dijk se refiere a los modelos mentales como lo construido en la memoria para comprender una información. Este modelo incluye mucho más conocimiento de lo que se relata en el texto. Una parte de esta información deriva de las noticias y representa los conocimientos convencionales de la vida cotidiana compartidos culturalmente, instaurados en la sociedad y construidos, representados o ratificados por los medios de comunicación. 
De forma similar, los lectores también tienen un modelo de contexto, el cual incluye información acerca de los objetivos del discurso, los actos comunicativos y las propiedades de la audiencia.

Se ha comentado en ocasiones que los modelos se basan en representaciones sociales o cogniciones sociales de la realidad. Si estas cogniciones acerca de los distintos grupos sociales son parecidas, se puede deducir que están controladas por los mismos patrones de interpretación, es decir, por la misma ideología que, en este caso, no se esconde en una estructura presente sutilmente, sino en la evidencia contextual que ello implica.

De tal manera, y teniendo en cuenta todos los procedimientos que involucra este análisis, entendemos, desde y con Teun van Dijk (1997 y 2003), que la importancia de trabajar estos diferentes niveles radica en comprender que los medios de comunicación no solamente son capaces de construir las diferencias culturales sobre la base de la propagación de estereotipos o prejuicios en el nivel formal y de significado de sus entregas noticiosas, sino que, además, pueden ir adaptando potencialmente nuestros modelos de pensamiento y representaciones de la realidad, ejerciendo poder tanto directa como indirectamente en la conciencia de las audiencias/lectores.

A modo de resumen, podemos decir que esta herramienta de análisis funciona operativamente para estudiar las noticias y describir y explicar en qué medida los medios de comunicación, al hacer referencia a ciertas temáticas, pueden transformarse en dispositivos propagandísticos y de discriminación.

\section{Consideraciones generales}

Como ya se dijo, esta propuesta de investigación pretende describir y reflexionar sobre los tratamientos informativos que realizaron dos medios escritos, uno peruano y otro boliviano, en relación con una noticia de impacto internacional que aconteció en Chile. Al describir sus contenidos y mediaciones a través de las representaciones practicadas por estos, se podrá comprender cómo dichas representaciones del suceso podrían reforzar "realidades" entre países, que ayudan a sostener imaginarios que, como estereotipos, se apartan de los discursos dialógicos e interculturales propios del periodismo transparente que debiera ejercer la prensa al reconocerse como una de las fuentes primarias de producción de imaginarios y prejuicios socioculturales.

\section{Bibliografía}

AbriL, Gonzalo (1997). Teoría general de la información. Madrid: Cátedra.

Austin Millán,Tomás. “Comunicación intercultural: fundamentos y suge- 
rencias" (2000). <http://www.lapaginadelprofe.cl/com/ComIntercult/ comintuno.htm>. [Consulta: 29 de diciembre del 2011).

Berger, Peter y Thomas Luckmann (1972). La construcción social de la realidad. Buenos Aires: Amorrortu.

Bracho, Aymara. "Análisis comparativo del tratamiento periodístico de la información internacional de los diarios El Universal, El Carabobeño y El Siglo, durante febrero de 2006". Tesis para optar el título de licenciada en Comunicación Social, mención Periodismo Impreso. San Diego-Carabobo, Venezuela: Universidad Arturo Michelena (UAM), 2006. <http:// espaciovirtual.wordpress.com/latesis\%E2\%80\%A6/>. [Consulta: 29 de diciembre del 2011].

Browne, Rodrigo y Pamela Romero (2010). "Análisis crítico del discurso (ACD) de la representación boliviana en las noticias de la prensa diaria de cobertura nacional: El caso de El Mercurio y La Tercera". Polis 26. Santiago de Chile: Universidad Bolivariana, <http://polis.revues. org/754>. [Consulta: 29 de diciembre del 2011].

BRowne, Rodrigo; del Valle, Carlos; Silva Echeto, Víctor; Carvajal, Julio y Alex Inzunza (2011). "Propuesta teórico-metodológica para un análisis crítico y complejo del discurso (ACCD) en la prensa de Chile y Perú. El ejemplo de $L a$
Cuarta y Ajá". Revista Estudios del Mensaje Periodístico, vol. 17, núm. 1. Madrid: Universidad Complutense de Madrid.

Browne Rodrigo; Inzunza Alex y Víctor Hugo Valenzuela (2009). "Periodismo intercultural: aproximaciones teórico-metodológicas para un análisis crítico de la construcción social de los medios de comunicación", en Carvajal, Julio y Gustavo Rodríguez (eds.). Comunicación informativa y nuevas tecnologías. Buenos Aires: Gran Aldea.

Carvajal, Julio (2007). “Análisis crítico a la gestión informativa desempeñada por los diarios El País, $A B C$ y La Razón, durante los sucesos del 11-M". Tesis para optar el grado de doctor en Organización y Gestión de la Empresa Informativa. Madrid: Universidad Complutense de Madrid.

Casero, Andreu (2004). "Informando del 'otro': Estrategias del discurso periodístico en la construcción de la imagen de los inmigrantes". Revista Sphera Publica 3. Murcia: Universidad Católica San Antonio de Murcia.

Del Valle, C. (2006). Comunicación participativa, estado-nación y democracia. Discurso, tecnología y poder. Temuco: Ediciones Universidad de La Frontera.

Fuentes, Juan Luis (2006). Comunicación estudio del lenguaje. Ciudad de México: Bibliográfica Internacional. 
Glasser, T. L., Awad, I. y J. W. Kim (2009). "The claims of multiculturalism and journalism's promise of diversity". Journal of Communication 59. International Communication Association (ICA).

Grifeu, J. M. (1991). Estructura general de la comunicación pública. Barcelona: Pòrtic.

Israel Garzón, Estrella (2006). Comunicación y periodismo en una sociedad global. Comunicar la diferencia. Sevilla: MAD Eduforma.

-. (2004). "Comunicación intercultural y construcción periodística de la diferencia". La iniciativa de Comunicación, marzo 2004. <http:// www.comminit.com/?q=mediadevelopment/node/149884>. [Consulta: 29 de diciembre del 2011].

—. (2002). "Comunicación intercultural para la formación de periodistas". Sala de Prensa 45, julio de 2002. <http://www.saladeprensa. org/art378.htm>. [Consulta: 29 de diciembre del 2011].

—. (2000). “Bases para el periodismo intercultural". Revista Latina de Comunicación Social 34. Islas Canarias: Universidad de la Laguna.

Martín Barbero, Jesús (1987). De los medios a las mediaciones. Comunicación, cultura y hegemonía. Barcelona: Gustavo Gili.

Mattelart, Armand y Michèle MatteLART (1997). Historias de las teorías de la comunicación. Barcelona: Paidós.
Mayorga, Alberto y Víctor González (2005). "Medios de comunicación y discurso hegemónico. Una aproximación empírica para comprender la configuración mediática y representación discursiva del Perú en la prensa chilena". Memoria del IV Seminario Latinoamericano de Investigación de la Comunicación: Urgencias Latinoamericanas en Investigación Comunicacional. Perspectivas crítico-epistemológicas. Bolivia: Universidad Andina Simón Bolívar.

McСомвs, Maxwell (1996). “Influencia de las noticias sobre nuestras imágenes del mundo", en Bryant, Jennings (ed.). Los efectos de los medios de comunicación. Barcelona: Paidós Ibérica.

Piñuel, José Luis y Carlos Lozano (2006). Ensayo general sobre la comunicación. Barcelona: Paidós.

Rodrigo Alsina, Miquel (2006). "Presentación: Miradas interculturales", en Rodrigo Alsina, Miquel (coord.). Comunicación 4, Revista Internacional de Comunicación Audiovisual, Publicidad y Estudios Culturales. Monográfico sobre comunicación intercultural. Anuario del Departamento de Comunicación Audiovisual, Publicidad y Literatura. Sevilla: Universidad de Sevilla, Facultad de Comunicación.

-. (2001). Teorías de la comunicación: Ámbitos, métodos y perspectivas. 
Barcelona: Bellaterra/Universitat Autònoma de Barcelona.

-. (1999). Comunicación intercultural. Barcelona: Anthropos.

—. (1993). "Per a una anàlisi constructivista del discurs emotiu". Anàlisi. Quaderns de comunicació $i$ cultura 15. Barcelona: Universidad Autónoma de Barcelona.

-. (1989). La construcción de la noticia. Barcelona: Paidós.

Romano, Vicente (2000). "Poder y comunicación". Laberinto 3. Málaga: Universidad de Málaga. <http:// laberinto.uma.es/index.php? option=com_content\&view=article \&id=79:poder-y-comunicacion\&catid $=37:$ lab3\&Itemid $=54>$. [Consulta: 29 de diciembre del 2011].

Serrano, Sebastiá (1984). La semiótica, una introducción a la teoría de los signos. Barcelona: Montesinos.

VAN DijK, Teun (2003a). "La multidisciplinariedad del análisis crítico del discurso: Un alegato a favor de la diversidad", en Wodak, Ruth y Michael Meyer (coords.). Métodos de análisis crítico del discurso. Barcelona: Gedisa.

- (2003b). Dominación étnica y racismo discursivo en España y América Latina. Barcelona: Gedisa.

- (1997). Racismo y análisis crítico de los medios. Barcelona: Paidós.

-. (octubre de 1994). "Conferencias de Teun van Dijk". Discurso, Poder y Cognición. $<$ http://www.discursos.org/ Art/Discurso,\%20poder\%20y\%20 cognici\%F3n\%20social.pdf>. [Consulta: 29 de diciembre del 2011].

-. (1990). La noticia como discurso: Comprensión, estructura y producción de la información. Barcelona: Paidós.

Vázquez Medel, Manuel Ángel (1999). "Los medios de comunicación y la construcción social de la realidad", en Chaparro, Manuel (ed.). La democratización de los medios. Sevilla: EMA-RTV. 
Anexo

Aplicación metodológica en los diarios El Comercio y La Razón

\section{El Comercio}

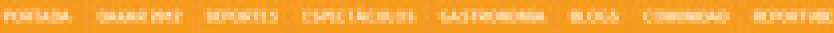

Bascart er unakediscrei - 웅

anpa mition:

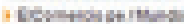

Minero boliviano decidió quedarse en Chile a pesar de tener autorización para viajar

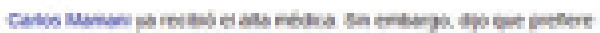

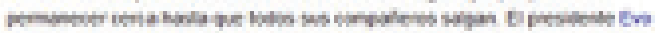

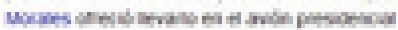

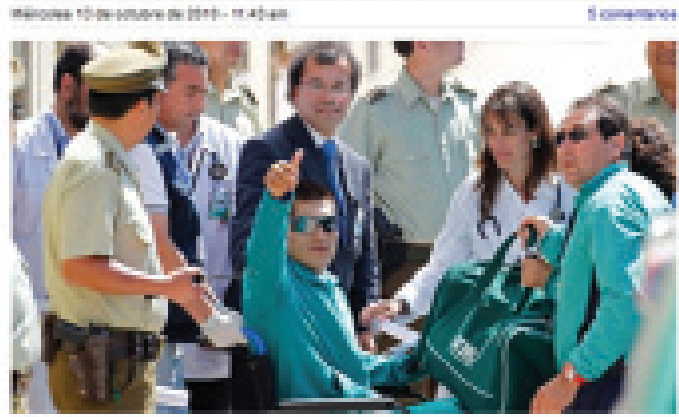

the

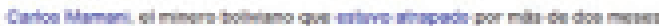

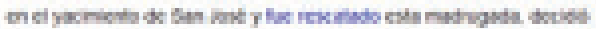

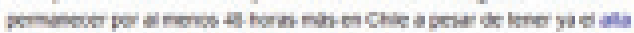

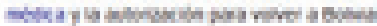

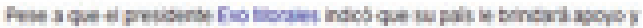

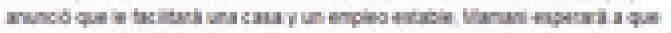

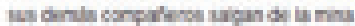

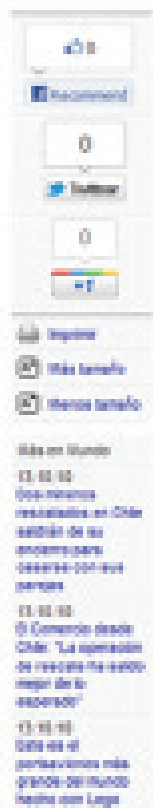

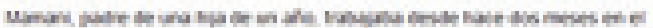

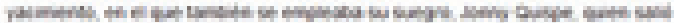

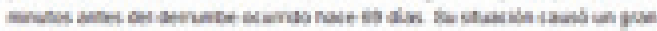

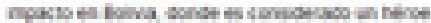

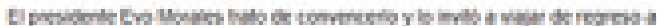

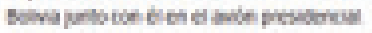

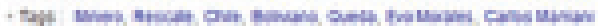

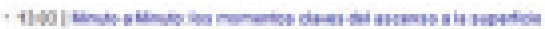

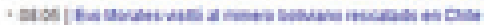

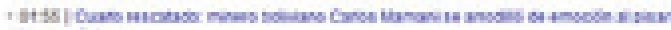
usutetes 


\begin{tabular}{|c|c|}
\hline & $\begin{array}{l}\text { excusa, ya que cuenta con todos los permisos médicos } \\
\text { y legales para regresar a su país de origen. Además, la } \\
\text { negativa de Mamani a los ofrecimientos de Evo Morales, } \\
\text { se conciben como un desplante y una falta de respeto al } \\
\text { presidente de Bolivia. } \\
\text { Por otra parte, se destacan las ansias por figurar mediá- } \\
\text { ticamente de Evo Morales y se entiende que estaría bus- } \\
\text { cando mejorar su imagen pública por medio de los ofreci- } \\
\text { mientos de ayuda a Mamani. } \\
\text { "Su situación causó un gran impacto en Bolivia, donde es } \\
\text { considerado un héroe" } \\
\text { Se muestra que los bolivianos habrían ensalzado la figura } \\
\text { de Carlos Mamani, ya que lo estimarían como un héroe. } \\
\text { Antecedente que cuestiona aún más la decisión de este } \\
\text { de permanecer en Chile, pues los héroes deben regresar } \\
\text { a sus respectivos países, ya que se tratan de figuras aso- } \\
\text { ciadas a la concepción de Nación. } \\
\text { b) De carácter explícito o directo: No hay }\end{array}$ \\
\hline $\begin{array}{l}\text { 2.- Plano Formal/texto- } \\
\text { contexto }\end{array}$ & $\begin{array}{l}\text { 2.1.- Estructuras formales sutiles: Se apela a construccio- } \\
\text { nes mentales en las que se presenta a Bolivia como un país } \\
\text { económicamente subdesarrollado, y, en oposición directa, } \\
\text { se muestra a Chile como un país estable y productivo eco- } \\
\text { nómicamente, al que pueden acudir los bolivianos en bús- } \\
\text { queda de bienestar. } \\
\text { 2.2.- Nivel contextual } \\
\text { El boliviano Carlos Mamani fue el único extranjero entre los } \\
33 \text { mineros que quedaron atrapados en el Yacimiento San } \\
\text { José (Atacama, Chile) el } 7 \text { de agosto del } 2010 \text { y que lue- } \\
\text { go fueron rescatados el } 13 \text { de octubre de ese mismo año. } \\
\text { Mamani empezó a trabajar en la mina } 5 \text { días antes del de- } \\
\text { rrumbe, recomendado por su suegro. } \\
\text { Si bien Mamani visitó Bolivia en octubre del } 2010 \text { y recibió } \\
\text { una oferta de trabajo en la jefatura de transportes de la esta- } \\
\text { tal YPFB-Transportes en Cochabamba, regresó a Chile junto } \\
\text { a su familia. }\end{array}$ \\
\hline
\end{tabular}

(continúa)

1 Es pertinente señalar que, ya que se trata del mismo acontecimiento noticioso, el nivel contextual de ambos análisis es el mismo. 
(continuación)

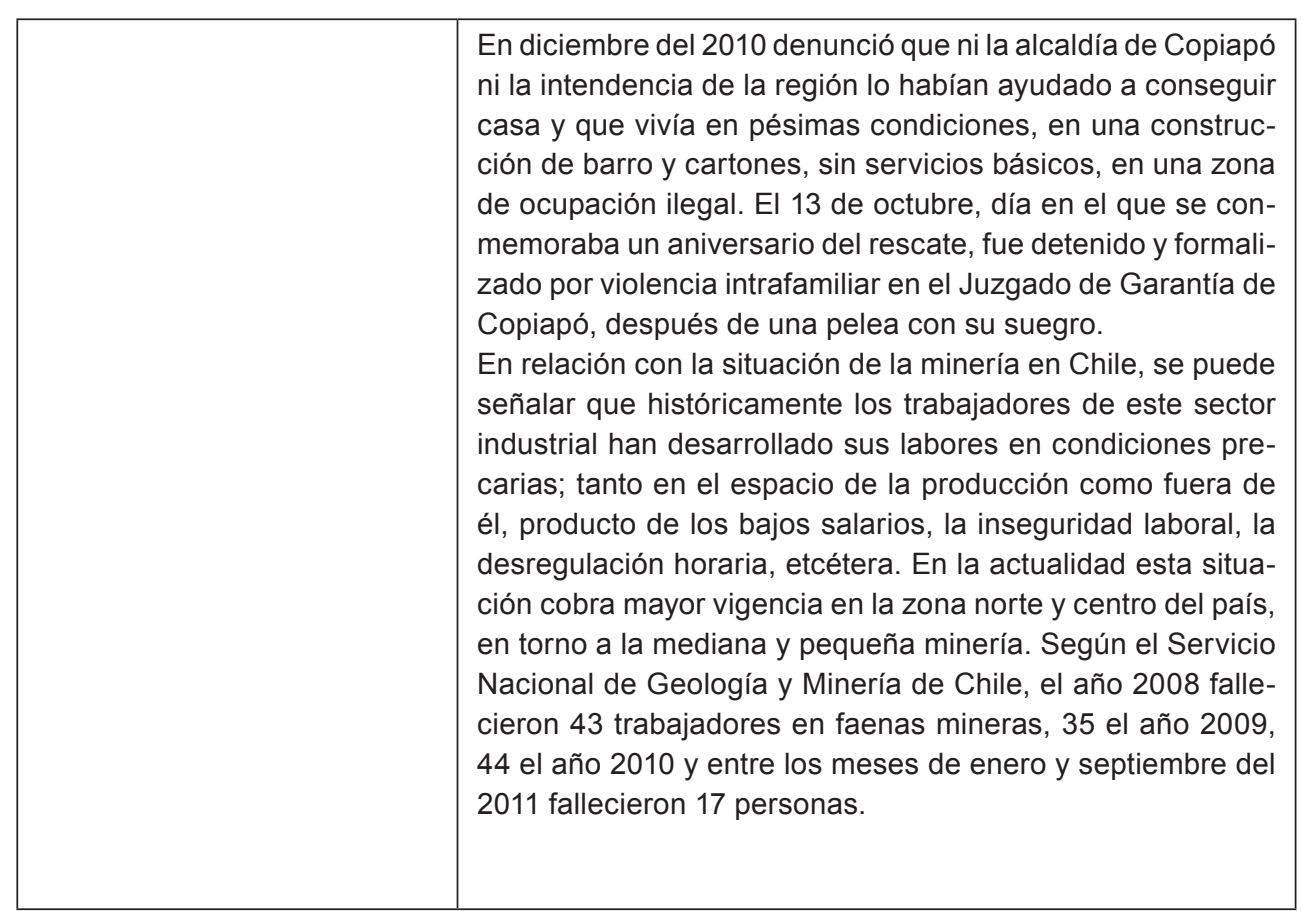




\section{laRazón}

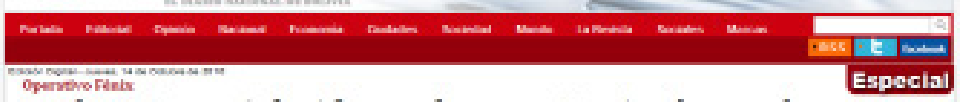

\section{Carlos Mamani decide quedarse en Copiapó, por el}

\section{momento}

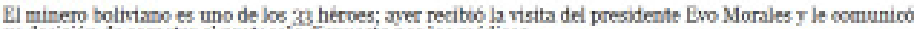

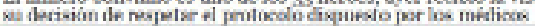

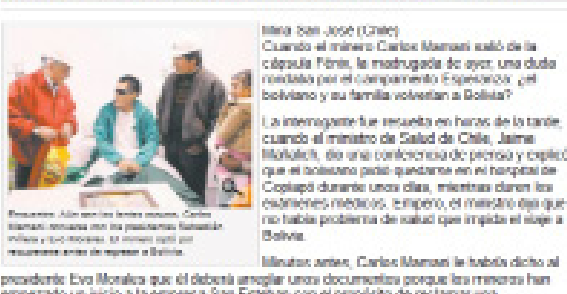

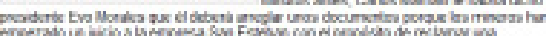

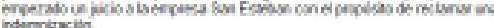

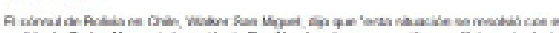

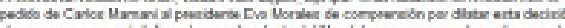

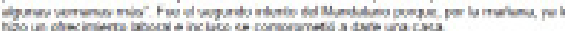

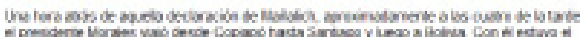

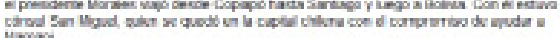

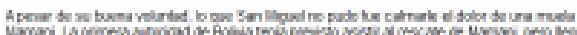

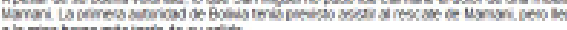

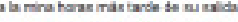

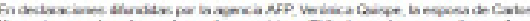

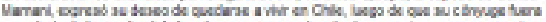

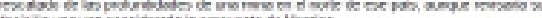

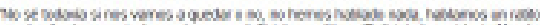

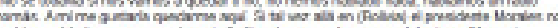

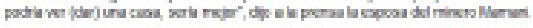

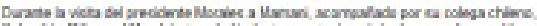

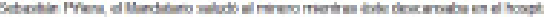

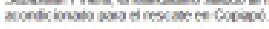

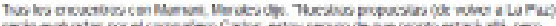

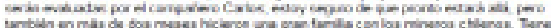

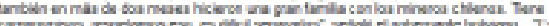

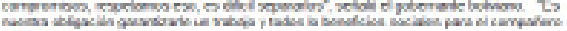

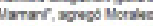

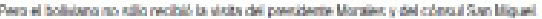

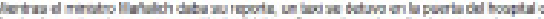

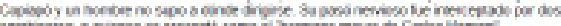

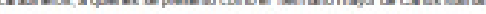

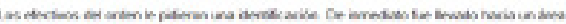

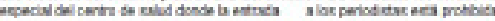

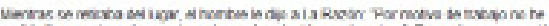

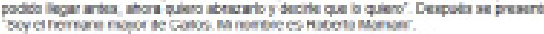

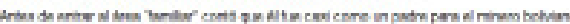

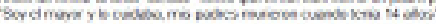

\section{Moraten arracece a Maven}

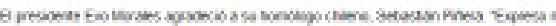

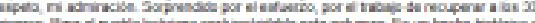

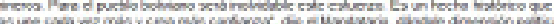
xincon NP

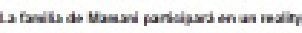

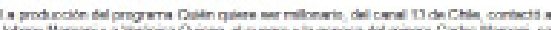

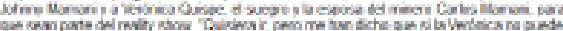

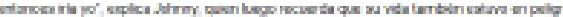

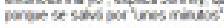

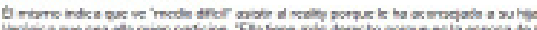

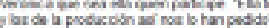

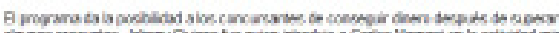

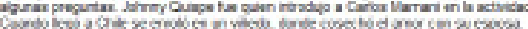

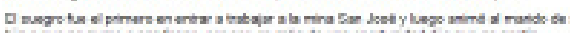

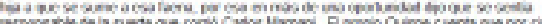

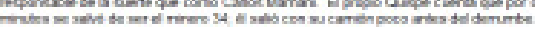

opiniones:

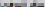

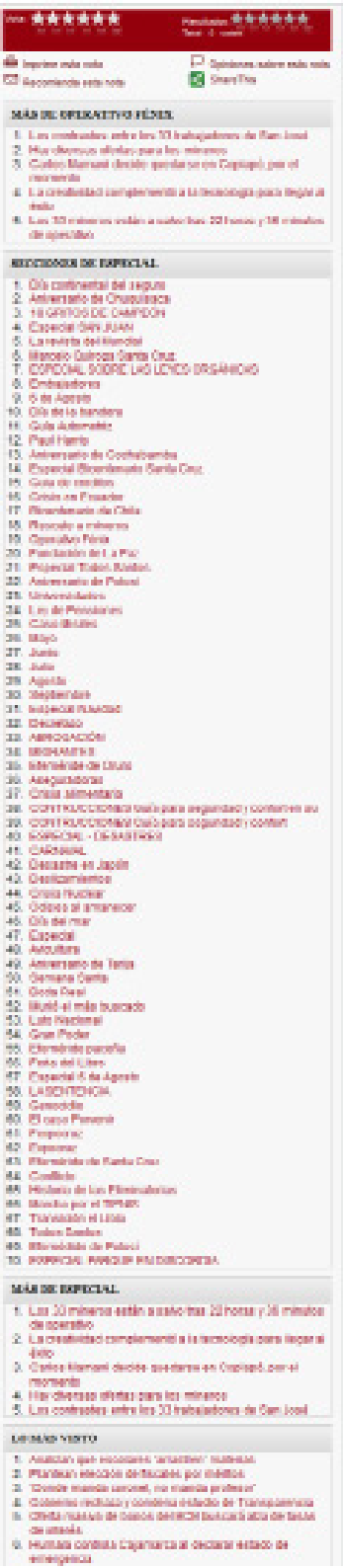




\section{TITULAR:}

Epígrafe: Operativo Fénix

Título: Carlos Mamani decide quedarse en Copiapó, por el momento

Bajada: El minero boliviano es uno de los 33 héroes; ayer recibió la visita del presidente Evo Morales y le comunicó su decisión de respetar el protocolo dispuesto por los médicos

Pie de Foto: Encuentro. Aún con los lentes oscuros, Carlos Mamani conversa con los presidentes Sebastián Piñera y Evo Morales. El minero optó por recuperarse antes de regresar a Bolivia.

\begin{tabular}{|c|c|c|}
\hline Periódico: La Razón & País: Bolivia & $\begin{array}{l}\text { Periodista: No se identifica, } \\
\text { pero se señala que algunas } \\
\text { informaciones pertenecen } \\
\text { a la agencia AFP (Agence } \\
\text { France-Presse) }\end{array}$ \\
\hline $\begin{array}{l}\text { Fecha: } 14 \text { de octubre del } \\
2010\end{array}$ & \multicolumn{2}{|c|}{$\begin{array}{l}\text { Ubicación: http://www2.la-razon.com/version_temp.php?A } \\
\text { rticleld=775\&Editionld=2737\&idp=10\&ids }=97\end{array}$} \\
\hline 1.- Plano Significado/texto & \multicolumn{2}{|c|}{$\begin{array}{l}\text { 1.1.- Nivel temático: significados globales } \\
\text { Carlos Mamani, boliviano, uno de los } 33 \text { mineros atrapa- } \\
\text { dos en la mina San José y que fue rescatado la madruga- } \\
\text { da de ayer, decidió quedarse en Copiapó para una revisión } \\
\text { médica. } \\
\text { El ministro de Salud de Chile, Jaime Mañalich, señaló que } \\
\text { no había problema de salud que impida a Mamani volver a } \\
\text { Bolivia. } \\
\text { Evo Morales, presidente de Bolivia, le hizo un ofrecimiento } \\
\text { laboral y se comprometió a darle una casa en su país. } \\
\text { Verónica Quispe, esposa de Carlos Mamani, declaró que le } \\
\text { gustaría quedarse a vivir en Chile. } \\
\text { La familia de Carlos Mamani fue invitada a participar en el } \\
\text { programa de concursos Quién quiere ser millonario en la te- } \\
\text { levisión chilena. }\end{array}$} \\
\hline & \multicolumn{2}{|c|}{$\begin{array}{l}\text { 1.2.- Nivel de significados locales } \\
\text { a) De carácter implícito o indirecto: } \\
\text { "ayer recibió la visita del presidente Evo Morales y le co- } \\
\text { municó su decisión de respetar el protocolo dispuesto por } \\
\text { los médicos" } \\
\text { En la bajada, parte fundamental y destacada de la noticia, } \\
\text { se exculpa a Carlos Mamani de sus deseos de permane- } \\
\text { cer en Chile, argumentando que sería por motivos médi- } \\
\text { cos, aunque en el segundo párrafo de esta noticia se indi- } \\
\text { ca que fue el propio Mamani quien solicitó quedarse en el }\end{array}$} \\
\hline
\end{tabular}




\begin{tabular}{|c|c|}
\hline & $\begin{array}{l}\text { que han sido invitados, y cuya presencia aún no es con- } \\
\text { firmada, es un programa de concursos llamado ¿Quién } \\
\text { quiere ser millonario?. Ambos formatos televisivos son } \\
\text { muy diferentes, y al utilizar la palabra reality se tiende a } \\
\text { pensar que la familia del minero boliviano sería la pro- } \\
\text { tagonista de un programa realizado especialmente para } \\
\text { ellos, en el que presentaría su vida y no en un programa } \\
\text { de concursos en el que se deben responder preguntas } \\
\text { de conocimiento general para obtener sumas de dinero } \\
\text { en un estudio de televisión. De esta manera, se sobredi- } \\
\text { mensiona la importancia del programa y la participación } \\
\text { en este. } \\
\text { b) De carácter explícito o directo: } \\
\text { "El minero boliviano es uno de los } 33 \text { héroes" } \\
\text { Se destaca el carácter de valentía y virtuosismo de } \\
\text { Mamani, como uno de los } 33 \text { mineros que sobrevivieron } \\
\text { al derrumbe de la mina San José. } \\
\text { "La producción del programa Quién quiere ser millona- } \\
\text { rio, del canal } 13 \text { de Chile, contactó a Johnny Mamani y a } \\
\text { Verónica Quispe, el suegro y la esposa del minero Carlos } \\
\text { Mamani, para que sean parte del reality show" } \\
\text { Hay una equivocación en los apellidos, por "Johnny } \\
\text { Mamani" se refiere a "Johnny Quispe", padre de la espo- } \\
\text { sa de Carlos Mamani, antecedentes que se prestan para } \\
\text { confusión, en plena ola mediática. }\end{array}$ \\
\hline \multirow[t]{2}{*}{$\begin{array}{l}\text { 2.- Plano Formal/texto- } \\
\text { contexto }\end{array}$} & $\begin{array}{l}\text { 2.1.- Estructuras formales sutiles: } \\
\text { Se alude a estructuras formales que se refieren a la miti- } \\
\text { ficación del minero boliviano Carlos Mamani como figu- } \\
\text { ra heroica. Por otro lado, se destacan las intensiones de } \\
\text { Evo Morales para utilizar el rescate y la imagen de Carlos } \\
\text { Mamani como estrategia política. Evo Morales se proyecta } \\
\text { como un Presidente cercano, empático y solidario. }\end{array}$ \\
\hline & $\begin{array}{l}\text { 2.2.- Nivel contextual: } \\
\text { El boliviano Carlos Mamani fue el único extranjero entre los } \\
33 \text { mineros que quedaron atrapados en el Yacimiento San } \\
\text { José (Atacama, Chile) el } 7 \text { de agosto del } 2010 \text {, y que lue- } \\
\text { go fueron rescatados el } 13 \text { de octubre de ese mismo año. } \\
\text { Mamani empezó a trabajar en la mina } 5 \text { días antes del de- } \\
\text { rrumbe, recomendado por su suegro. }\end{array}$ \\
\hline
\end{tabular}




\begin{tabular}{|l|l|}
\hline Si bien Mamani visitó Bolivia en octubre del 2010 y recibió \\
una oferta de trabajo en la jefatura de transportes de la esta- \\
tal YPFB-Transportes en Cochabamba, regresó a Chile junto \\
a su familia. \\
En diciembre del 2010 denunció que ni la alcaldía de Copiapó \\
ni la intendencia de la región lo habian ayudado a conseguir \\
casa y que vivía en pésimas condiciones, en una construc- \\
ción de barro y cartones, sin servicios básicos, en una zona \\
de ocupación ilegal. \\
El 13 de octubre, día en el que se conmemoraba un aniver- \\
sario del rescate, fue detenido y formalizado por violencia \\
intrafamiliar en el Juzgado de Garantía de Copiapó, después \\
de una pelea con su suegro. \\
En relación con la situación de la minería en Chile, se puede \\
señalar que históricamente los trabajadores de este sector \\
industrial han desarrollado sus labores en condiciones pre- \\
carias; tanto en el espacio de la producción como fuera de \\
él, producto de los bajos salarios, la inseguridad laboral, la \\
desregulación horaria, etcétera. En la actualidad esta situa- \\
ción cobra mayor vigencia en la zona norte y centro del país, \\
en torno a la mediana y pequeña minería. Según el Servicio \\
Nacional de Geología y Minería de Chile, el año 2008 falle- \\
cieron 43 trabajadores en faenas mineras, 35 el año 2009, \\
44 el año 2010 y entre los meses de enero a septiembre del \\
2011 fallecieron 17 personas. \\
\hline
\end{tabular}

